\title{
Intersetorialidade nas Políticas Públicas
}

\section{Intersectoriality in Public Policies}

\author{
Mariangela Belfiore Wanderley ${ }^{a}$ \\ (1) https://orcid.org/0000-0003-3894-6478 \\ Maria Lúcia Martinellia \\ (D) https://orcid.org/0000-0001-9124-2846 \\ Rosangela Dias O. da Paz \\ (1) https://orcid.org/0000-0003-3547-1286
}

ste número da Revista Serviço Social \& Sociedade vem a público
em um momento especialmente importante para tratarmos de
questões relativas à proteção social e à intersetorialidade. Torna-se um imperativo ético dar visibilidade à nova morfologia do capitalismo, que em seu estágio financeiro avançado cria novas modalidades e dominação que repercutem em todas as esferas da vida, com fortes expressões até mesmo em nossa subjetividade.

Na interpretação de Pierre Dardot e Christian Laval, da Universidade Paris-Ouest-Nanterre-La Défense, grandes estudiosos dessa temática, estamos diante de uma nova racionalidade onde predomina a razão neoliberal (2016, p. 189). Essa é a nova razão do mundo, a razão do capitalismo contemporâneo que se faz acompanhar de uma noção de liberdade neoliberal, extraída da concorrência mercantil, que penetra em todas as tramas do tecido social. O Estado, na visão dos autores, torna-se um ente horizontal, em situação de competição com todos os outros agentes econômicos privados, desobrigando-se da oferta de políticas públicas efetivamente universais (2016, p. 197-201). 
Antes de serem pensados como cidadãos, detentores de direitos universais garantidos pela Carta Magna dos países, são agora apenas “cidadãos clientes" submetidos a uma lógica gerencialista, predominantemente financeira (Dardot e Laval, 2016, p. 202). Desnecessário dizer o quanto essa nova racionalidade do capitalismo produz crises de governabilidade, fragmentando as ações intersetoriais no campo das políticas públicas.

Nessa direção, a política social brasileira só pode ser concebida inserida no contexto histórico, político, econômico e social, como resultado da disputa de projetos e interesses e da pactuação entre as diversas forças sociais presentes na sociedade, que se materializam em um conjunto de regulações e ações do Estado.

No caso brasileiro, a configuração do Estado tem a setorização e fragmentação como constitutivas da estruturação histórica das políticas públicas, concebidas e organizadas para serem implementadas isoladamente, sem que haja planejamentos conjuntos e ações articuladas. A lógica setorial expressa-se na estrutura administrativa, dos três níveis de governo, na formulação, coordenação e execução dos serviços públicos, e via de regra, cada área da política pública especializa-se com a definição de normativos, procedimentos buscando recursos (humanos, físicos e orçamentários) para sua viabilização.

A consequência da setorização tem sido observada ao longo das diferentes gestões públicas, pela desarticulação, fragmentação e sobreposição das ações, além de expor as famílias, indivíduos e grupos atendidos pelas políticas a um paralelismo de intervenções e, muitas vezes, à duplicidade de cadastros e procedimentos para acesso aos serviços públicos.

A intersetorialidade como estratégia de gestão pública democrática, para responder à setorização e à fragmentação, pressupõe decisão política, articulação entre os setores e complementariedade das ações, buscando um olhar para a totalidade das manifestações da questão social e dos cidadãos que demandam atendimento público.

A articulação, intersetorialidade e a complementaridade dos serviços das políticas sociais contribui para a qualidade de vida, melhorando 
sensivelmente as condições de vida da população. Constituem-se em desafios permanentes para as diferentes gestões municipais, estaduais e federal.

Do ponto de vista da gestão pública democrática, a intersetorialidade desafia a política no compartilhamento de responsabilidades e atribuições e possibilita maior racionalidade dos recursos.

Para Junqueira (2005, p. 4),

[...] a intersetorialidade constitui uma concepção que deve informar uma nova maneira de planejar, executar e controlar a prestação de serviços. Isso significa alterar toda a forma de articulação dos diversos segmentos da organização governamental e dos seus interesses.

É nos territórios que a intersetorialidade se materializa como condição essencial para a implementação de serviços públicos integrados, como resposta à multidimensionalidade da pobreza e à segregação socioespacial. Assim, territorialidade e intersetorialidade potencializam as intervenções públicas, ampliando possibilidades e efetividade das ações integradas e desenvolvidas através da construção de diagnósticos, programas, ações e com responsabilidades compartilhadas (Paz e Taboada, 2010).

Podemos afirmar que o horizonte da intersetorialidade das políticas públicas consubstancia-se na melhora das condições de vida da população, na otimização e utilização dos recursos (financeiros, materiais e humanos) e nos ganhos de escala e de resultados. Mas é preciso esclarecer que a intersetorialidade não pode ser vista como iniciativa individual de profissionais ou equipes, requer decisões institucionais e políticas nos níveis de planejamento e de execução que rompam com a cultura política da setorização que tem sido reforçada com as práticas de negociação de cargos entre partidos e parlamentares que apoiam determinadas gestões, em nome da governabilidade, sem um programa de ação integrado. 
Assim, o desafio está posto na construção de bases políticas e de mecanismos intersetoriais que estabeleçam a comunicação, articulação e a formação de uma nova cultura organizacional entre órgãos e agentes públicos. "Essas mudanças só serão efetivas quando houver nova maneira de olhar a realidade social, de lidar com ela, o que significa mudar práticas organizacionais, que só ocorrem quando há transformação de valores e da cultura das organizações" (Junqueira, 2005, p. 6). Dessa forma a criação de sistemas e fluxos de comunicação, o planejamento e as definições de estratégias entre as diversas estruturas e agentes públicos e privados, possibilitam construir uma nova cultura organizacional e o atendimento integral das demandas.

Entretanto, com o neoliberalismo e as mudanças no modo de acumulação capitalista, as políticas sociais são impactadas pela restrição de orçamento e, consequentemente, pelo aprofundamento da fragmentação, da focalização, da privatização e/ou terceirização e dos serviços públicos. Como afirma Harvey (1996) o capitalismo se transforma em um novo padrão de acumulação flexível e numa programática neoliberal.

Soma-se a esse cenário o desmonte dos direitos e das políticas sociais em curso no Brasil desde o golpe parlamentar de 2016, e aprofundadas com a implementação da agenda de reformas do governo do presidente Jair Bolsonaro, as quais atacam a cidadania e a democracia, destruindo os avanços alcançados nos últimos 30 anos e buscando a implantação de Estado mínimo liberal.

A democracia direta vem sofrendo inúmeros golpes. Reconhecidos espaços de participação popular e de gestão democrática, conquistas dos movimentos sociais, estão sendo extintos ou recompostos limitando a participação da sociedade civil. As lideranças populares e os movimentos sociais vêm sofrendo perseguições políticas e criminalização das lutas e das legítimas manifestações e expressões públicas.

É visível o desmonte das políticas públicas desfigurando os sistemas de proteção social e aumentando as desigualdades e o empobrecimento, no campo e nas cidades, das camadas mais vulneráveis da sociedade 
brasileira. Um número cada vez maior de moradores de rua ocupa as calçadas das cidades, adensam-se as favelas, cortiços, ocupações que permanecem sem acesso aos serviços e equipamentos das políticas sociais.

Os artigos que integram o presente número afirmam o quanto a intersetorialidade das políticas é indispensável neste momento de agravamento da questão social, pelo desemprego, pelo crescimento da desigualdade e da pobreza.

Já na abertura deste número, apresentamos o artigo que trata do capitalismo dependente e as origens da questão social no Rio de Janeiro, trazendo o registro das lutas das classes subalternas contra a exploração do trabalho, no período de 1850 a 1922.

Os desafios da gestão das políticas, das conexões intersetoriais e inclusive da gestão territorial são trabalhados nos seguintes artigos: Os desafios da gestão territorial na proteção básica em uma metrópole; Primeiro Plano Nacional de Segurança Alimentar; O Bolsa Família e seus impactos na questão laboral de beneficiários do município de São Luís.

Vale ressaltar que todos estão baseados em pesquisas e evidenciam o quanto essas políticas são fundamentais e como estão sofrendo retração de ofertas em tempos de políticas conservadoras neoliberais.

Um ponto em comum nesses artigos, e nos demais que tratam dessa temática, é a valorização da necessária articulação de ações de cunho intersetorial e adoção de uma perspectiva de transversalidade nas políticas com vistas a um modelo participativo que envolva também a sociedade civil.

Um outro conjunto de artigos põe em destaque o quanto essa nova racionalidade do capital criou um sistema disciplinador tal que a responsabilidade do Estado é deslocada para o cidadão, que é levado a cada momento a assumir a gestão pessoal do risco social, sentindo-se permanentemente avaliado em função dos resultados obtidos (Dardot e Laval, 2016, p. 201). Essa realidade está bem configurada nos artigos Envelhecimento, família e políticas públicas; Sentidos de família em três 
políticas sociais; Serviço Social e Poder Judiciário, e O caráter ontológico na determinação social da saúde, os quais, além de ressaltarem os desafios da relação Estado-família na proteção social, buscam, também, marcar de modo significativo o papel de participantes efetivos das ações profissionais.

A proposta de uma agenda de educação permanente por parte dos Assistentes Sociais do Poder Judiciário e a luta dos profissionais da saúde para dar evidência ao caráter ontológico do processo saúde-doença são expressões concretas de uma busca de reconhecimento e superação do ocultamento do sentido de sujeitos que essa razão do mundo produz.

É indispensável citar o artigo intitulado Karl Marx e a economia política: da rejeição moral à assimilação crítica, no qual as categorias trabalho abstrato e força de trabalho são situadas de modo histórico, destacando a força propulsora de uma análise econômica inovadora.

Em tempos obscuros e de aprofundamento do conservadorismo, a busca do "inédito viável" de Paulo Freire nos provoca não apenas a resistir, mas construir alternativas e caminhos coletivos que fortaleçam a cidadania, preservem os direitos sociais e afirmem a democracia.

\section{Referências}

DARDOT, Pierre; LAVAL, Christian. A nova razão do mundo: ensaio sobre a sociedade neoliberal. Trad. Mariana Echalar. 1. ed. São Paulo: Boitempo, 2016.

JUNQUEIRA, L. A. P. Articulações entre o serviço público e o cidadão. In: X Congreso Internacional del CLAD sobre la Reforma del Estado y de la Administración Pública. Santiago, Chile, oct. 2005.

HARVEY, D. Condição Pós-Moderna: uma pesquisa sobre as origens da mudança cultural. Trad. Adail Ubirajara Sobral e Maria Stela Gonçalves. 6. ed. São Paulo: Edições Loyola, 1996.

RAICHELIS, Raquel; VICENTE, Damares; ALBUQUERQUE, Valéria (Orgs.). A nova morfologia do trabalho no Serviço Social. São Paulo: Cortez, 2018.

PAZ, Rosangela D. O. da; TABOADA, Kleyd Junqueira. Conceitos básicos para intervenções habitacionais. In: Trabalho social em programas e projetos de habitação de interesse social. Ministério das Cidades. Curso a Distância, 2010. 


\section{Sobre as autoras}

MARIANgela Belfiore WANDERLEy - Assistente social, professora associada do Departamento de Política e Gestão. Docente do Programa de Pós-Graduação em Serviço Social.

E-mail: mariangela.belfiore@gmail.com

MARIA LÚcia MARTINELli - Assistente social, doutora em Serviço Social. Docente e pesquisadora em Serviço Social.

E-mail:mlmartinelli@terra.com.br

Rosangela Dias O. DA Paz - Assistente social, doutora em Serviço Social. E-mail: rosapaz@uol.com.br. 